\title{
ASSESSMENT OF COMMUNITY EMPOWERMENT IN A NEW CURRICULUM AT COLLEGE OF MEDICINE, UNIVERSITY OF BISHA, SAUDI ARABIA
}

\author{
Abdullah M. AL-Shahrani \\ Department of Family Medicine, College of Medicine, University of Bisha, Bisha, Saudi Arabia
} Correspondence: Abdullah M.

AL-Shahrani

ab_alshahrani@ub.edu.sa P.O. Box 1290, Bisha, Saudi Arabia

\section{ABSTRACT}

Introduction: Health institution has a vital role in community empowerment process to promote the participation of people, organizations and communities. The aim of this study was to review the innovative curriculum features of Bisha University College of Medicine (UBCOM) and its intended role in empowering local community in Southern of Saudi Arabia. Methods: It was a qualitative descriptive study for UBCOM curriculum and its main feature. UBCOM adopting problem based innovative curriculum was based on the southern Saudi community need. Data regarding the curriculum and relevant data were obtained from the college information canter. The small group discussion included four experts. The overall assessment for the relevant domains and items were obtained and statically analyzed.

Results: Bisha University College of medicine committed to graduate competent, accountable and lifelong learner physicians, through the "BISHA" model. These concepts were translated to real medical education program, adopted with promising outcome. UBCOM intended to have significant and direct impact on the health care needs of the community and region. It will share in community empowerment and established strong network and collaborators. The overall assessment by the four experts gave scores for three relevant domains in related to innovation and community empowerment was scored $73.7 \%$. Conclusion: The curriculum of College of Medicine University of Bisha is directed to graduate doctors to strength community empowerment and social attachment and accountability.

Keywords: Curriculum, Community, Empowerment, Bisha, Saudi Arabia

\section{INTRODUCTION}

Comav ommunity empowerment approaches have been proven to be powerful tools for solving local health problems. However, education and health care are two very important aspects and essential indicators in determining how "healthy" a nation is ${ }^{(1)}$.

Community empowerment is understood as a process or as an outcome ${ }^{(2-5)}$. This enables communities to assume power to act effectively in order to change their lives and environment which can be through the process of empowerment ${ }^{(6-8)}$. The community empowerment process promotes the participation of people, organizations and communities for increased individual and community control, political efficacy, improved quality of life and social justice ${ }^{(9)}$. The primary concept is to mobilize local communities to address their health and social needs and to work inter-sectorally to solve local problems ${ }^{(5)}$. Despite the wide use of empowering strategies in health and social development interventions and by many researchers ${ }^{(9)}$, there seems to be no consensus on agreed methods or universally accepted measurement tools to assist in the evaluation of the community empowerment process. The aim of this study was to assessment the new curriculum of College of Medicine University of Bisha, Saudi Arabia and its intended role in community empowerment.

\section{METHODS}

It was a qualitative descriptive study addressing curriculum of the college of medicine university of Bisha with in-depth analysis of its main feature and characteristics since the establishment till present (20122018).

The setting of this study was Bisha University College of medicine (UBCOM), which was established to serve local community in 


\section{Abdullah.}

Southern Saudi Arabia and adopting a problem based innovative curriculum based on community need. In addition to mission, vision and objectives of the college, the curriculum was reviewed and the principle document on its endorsement was reviewed and senior college among the founders was interviewed also.

Data regarding the curriculum and relevant information were retrieved from the college information center. The small group discussion included four experts' evaluators. Their selection criteria were holding degree in medical education, an experience of at least five years in undergraduate teaching and curriculum management and with different academic background. Components and items of the discussion were the features and community empowerment in the curriculum already adopted in the college program. They were provided with AGREE instrument check list modified from Appraisal of Guidelines for Research \& Evaluation (Agree) ${ }^{(10)}$. AGREE instrument modified check list was used to fit the two tested items, the innovation and the community empowerment. Three domains were assessed; scope \& purpose, stake holder involvement and applicability. Response scale each domain is rated on a 4-point scale ranging from 4 'strongly agree' to 1 'strongly disagree', with two mid points: 3 'Agree' and 2 'Disagree'. The scale measured the extent to which item has been fulfilled. The overall assessment for the relevant domains and items was obtained. Statistical analysis and calculation were managed and done in excel program. Ethical approval to conduct the research was obtained from the research and ethics committee of the College of Medicine University of Bisha.

\section{RESULTS}

Program was been established according to the Royal Decree which addresses national and local health needs and was been reflected on the development plans all over the kingdom.

The health sector is one of the areas which have great attention to achieve the set goals of providing the best services for the societies that meet their health needs. This has been evident in the development of health facilities

\section{Zagazig University Medical Journals}

and the increase in the number of human resources working in it.

This development needs to be supported by more increase in the rate of health workforces in relation to the population and to increase proportion of the national workforce, the Saudi physicians accounting for less than $30 \%$ of the total working physicians in the kingdom. This needs to increase the workforce through graduation from medical colleges.

Presence of a medical college in any region could add to the development of health in the region by multi-factors; increase in the workforce for health both in quantity and quality through its faculty members having different specialties and expertise, and provision of holistic healthcare services, the partnership and strategic alliance with the health service and the society and through research that address the priority health problems.

The medical school in Bisha University worked in close partnership with the concerned sectors to fulfill the health strategic goals and objectives through increase of the numbers of physicians. It could be an addition to the development of medical education nationally, regionally and internationally.

The relevance of the program to the mission and goals of the institutions concerned with physical and mental health of the community as a whole and as individuals which is the principal pillar for an institution of innovation and knowledge and productive community.

UBCOM committed to graduate competent, professional and lifelong learner physician through the BISHA model:

B-Best medical education environment.

I- Intersectoral and community participation.

S- Scientific research.

$\mathrm{H}-$ Holistic health care approach.

A- Accountability and leadership

Major strategies were the development of an outcome based, integrated curriculum meeting the principles of social accountability and the graduate competencies. This was beside the use of authentic teaching and learning techniques that are student's centered (Problem-based, case-based, etc.)

The strategies were adopted for development of an outcome based curriculum that meets 


\section{Abdullah.}

the principles of social accountability and the graduate competencies. Through, appreciated team work, institutional partnership with all stakeholders to foster of research culture and evidence based practice.

The innovative, outcome based curriculum has been developed and adopted in fulfillment of the requirement of the National Commission for Academic Accreditation and Assessment (NCAAA) which was established with responsibility for determining standards and procedures for accreditation and quality assurance and accrediting postsecondary institutions and programs within the Kingdom of Saudi Arabia, in accordance with the Saudi-MED domains.

The safe guarding of the implementation are; weekly Faculty Development Activity (FDA), clear Assessment Guidelines, E-Learning \& Maximum Utilization of Technology by satisfactory training on Blackboard \& other elearning tools for both student and faculty members. Beside, early exposure to Clinical Settings (EECS), through; Integration, well

\section{Zagazig University Medical Journals}

equipped basic science \& clinical skill labs and bed side teaching student early improve their clinical skills.

The overall assessment by the four experts gave scores for the three relevant domains in related to Innovation and community empowerment was scored $73.7 \%$, with over all excellent and very good for the community issues in the curriculum (Table 1).

Community engagement takes a variety of forms in UBCOM. Many organizations including schools, health services, government departments and planners and need to consult communities about a range of issues. By involving the community in meaningful ways, this consultation can be more than tokenism. Community leaders were also represented in the UBCOM research and research ethics committees.

Community engagement by social change movements and community groups are adopted in UBCOM by ensuring social accountability all through the educational process.

Table 1: Overall assessment by the four experts gave scores for relevant Domains and items

\begin{tabular}{|c|c|c|c|c|}
\hline \multicolumn{5}{|c|}{ Domain 1 (Scope and purpose) } \\
\hline Appraiser & Innovation & $\begin{array}{l}\text { Community } \\
\text { empowerment }\end{array}$ & Total & Scaled domain score \\
\hline Expert 1 & 3 & 3 & 6 & \multirow{5}{*}{$83 \%$} \\
\hline Expert 2 & 3 & 4 & 7 & \\
\hline Expert 3 & 4 & 4 & 8 & \\
\hline Expert 4 & 4 & 3 & 7 & \\
\hline Total & 14 & 15 & 28 & \\
\hline \multicolumn{5}{|c|}{ Domain 2 (Stake holder Involvement) } \\
\hline Appraiser & Innovation & $\begin{array}{l}\text { Community } \\
\text { empowerment }\end{array}$ & Total & Scaled domain score \\
\hline Expert 1 & 3 & 4 & 7 & \multirow{5}{*}{$70 \%$} \\
\hline Expert 2 & 2 & 3 & 5 & \\
\hline Expert 3 & 3 & 3 & 6 & \\
\hline Expert 4 & 3 & 4 & 7 & \\
\hline Total & 11 & 14 & 25 & \\
\hline \multicolumn{5}{|c|}{ Domain 3 (Applicability) } \\
\hline Appraiser & Innovation & $\begin{array}{l}\text { Community } \\
\text { empowerment }\end{array}$ & Total & Scaled domain score \\
\hline Expert 1 & 2 & 4 & 6 & \multirow{5}{*}{$75 \%$} \\
\hline Expert 2 & 3 & 3 & 6 & \\
\hline Expert 3 & 3 & 4 & 7 & \\
\hline Expert 4 & 4 & 3 & 7 & \\
\hline Total & 12 & 14 & 26 & \\
\hline
\end{tabular}

For each domain

Maximum possible score $=4$ (strongly Agree) x 2 (items) x 4 (appraisers) $=32$

Minimum possible score $=1$ (strongly disagree) $\times 2$ (items) $\times 4$ (appraisers) $=8$

The scaled domain score was:

(Obtained score

(Maximum possible score - Minimum possible score).

Minimum possible

score) 


\section{DISCUSSION}

The study findings highlighted the importance of establishing a new medical college based on innovative curriculum and after situation analysis was performed. It was intended to have significant and direct impact on the health care needs of the community and region. It was designed to share in community empowerment and established strong network and collaborators in accordance of the SaudiMED framework ${ }^{(11)}$. This represented a national standard for Saudi medical graduates, and intended to ensure that they have attained the competencies necessary to be a successful physician. It entailed 6 competencies including: scientific approach to practice, patient care, community-oriented practice, communication and collaboration, professionalism, and research and scholarship.

The curriculum can best be described as "SPICES model":

S: Spiral,

P: Problem based learning,

I: Integrated,

C: Community based,

E: Elective courses,

S: Student-centered.

In the academic literature it is generally considered more insightful to define empowerment as a process rather than an outcome. In 1986, the Ottawa Charter identified community empowerment as being a central theme of health promotion discourse. Community empowerment became a topical issue in the health promotion literature soon afterwards, though its roots also come from earlier literature in community psychology, community organizing and liberation education $^{(5)}$. Since the late 1970 s, the notion of empowerment has appeared with increasing frequency in discussion of preventive social and community intervention. While the idea of empowerment is intuitively appealing both for theory and practice, its applicability has been limited by continuing conceptual ambiguity ${ }^{(12)}$. Also the interaction between both process and outcome has been highlighted. Health and social science research relevant to both the role of powerlessness as a risk factor for disease, and the role of empowerment as a health-enhancing strategy (13). Potentially, empowerment has much to offer health promotion. However, some caution needs to be exercised before the notion is wholeheartedly embraced as the major goal of health promotion. The lack of a clear theoretical underpinning, distortion of the concept by different users, measurement ambiguities, and structural barriers make 'empowerment 'difficult to attain (4). Laverack's conceptualization of community empowerment is a 'dynamic continuum' from individual action to collective social and political change ${ }^{(5)}$.

\section{Conclusion and recommendations}

The study concluded that the importance of UBCOM in empowering community, so regular comprehensive evaluation of the intended role in social accountability and community empowerment are needed. Colleges of medicines curricula should considered the local community empowerment as priority learning strategies and should be modified their curriculum to match the need of their communities.

\section{Limitation of the study}

The limitation for this study was that UBCOM is a newly established college and further comprehensive assessment is advisable.

\section{Acknowledgement:}

Acknowledgement to academic staff of the University Of Bisha College of Medicine, curriculum committee member and the external reviewers. Local community leaders who participated in the formulation of the college vision and regularly attend college advisory committee meetings.

\section{Conflict of interest}

No conflict of interest was reported

Funding:

None

\section{REFERENCES}

1. Kasmel A, Andersen PT. Measurement of community empowerment in three community programs in Rapla (Estonia). Int $\mathrm{J}$ Environ Res Public Health. 2011;8(3):799-817.

2. Swift C, Levin G. Empowerment: An emerging mental health technology. J Prim Prev, 1987; 8, 7194. 


\section{Abdullah.}

3. Bernstein E, Wallerstein N, Braithwaite R, Gutierrez L, Labonte R, Zimmerman M. Empowerment forum: a dialogue between guest editorial board members. Health Education Quarterly. 1994; 21, 281-294.

4. Rissel C. Empowerment: the holy grail of health promotion? Health Promot Int. 1994; 9:39-47.

5. Laverack G, Wallerstein N. Measuring community empowerment: a fresh look at organizational domains. Health promotion international, 2001; 16(2): 179-185.

6. Minkler M. Community organizing among the elderly poor in the United States: A case study. Int J Health Serv, 1992; 22, 303-316.

7. Fawcett SB, Paine-Andrews A, Francisco VT, Schultz $\mathrm{J}$, Richter KP, Berkley-Patton J, et al. Evaluating community initiatives for health and development. WHO Reg Publ Eur Ser, 2001;(92):241-70

8. Rich MJ, Stoker RP. Rethinking empowerment: Local empowerment zone programs. Urb Aff Rev, 2009; 45, 775-796.

9. Makara P. Policy implications of differential health status in East and West Europe. The case of

\section{Zagazig University Medical Journals}

Hungary. Social Science \& Medicine, 1994; 39.9: 1295-1302.

10. Brouwers M, Kho ME, Browman GP, Cluzeau F, Feder G, Fervers B, et al. on behalf of the AGREE Next Steps Consortium. AGREE II: Advancing guideline development, reporting and evaluation in healthcare. Can Med Assoc J. Dec 2010, 182:E839842; doi: 10.1503/cmaj.090449. Available at: https://www.agreetrust.org/wpcontent/uploads/2013/10/AGREE-II-Users-Manualand-23-item-Instrument_2009_UPDATE_2013.pdf

11. Zaini RG, Bin Abdulrahman KA, Al-Khotani AA, AlHayani AM, Al-Alwan IA, Jastaniah SD. Saudi Meds: a competence specification for Saudi medical graduates. Medical teacher. 2011;33(7):582-4.

12. Kieffer CH. Citizen empowerment: A developmental perspective. Prevention in Human Services, 1984; 3.23: 9-36.

13. Wallerstein N. Powerlessness, empowerment, and health: implications for health promotion programs. American journal of health promotion, 1992; 6.3: $\quad 197-205$ 